\author{
NAZRINA HAQUE \\ BRAC University, Dhaka, Bangladesh
}

\title{
DOES TECHNOLOGICAL INVESTMENT HAVE AN IMPACT ON OUTWARD FOREIGN DIRECT INVESTMENT? A MICROECONOMETRIC ANALYSIS ON INDIAN MANUFACTURING FIRMS
}

\begin{abstract}
:
The main purpose of this paper is to look for characteristics that determine Outward FDI with microeocnometric techniques on firm level data. Many studies have explored different dimensions of trade but little trace has been found on outward FDI which is an important channel of global exposure. To explore this area, this paper works with firm level data of Indian manufacturing firm after trade liberalization, aiming to investigate the relationship between technological investment and outward FDI. As the study is dealing with limit observation in the dependent variable, implies estimating the model with censored data, the best approach to estimate the model could have been with Tobit model. The first model is the standard Tobit model, taking the intensity of outward FDI as dependent variable and technological investment with other control variables as independent variables along with time and year dummy. It showed, there is a significant and positive relation between technological investment and outward FDI. Other characteristics were found statistically significant in choosing outward FDI. This standard Tobit model did not account for potential endogeneity, which was controlled in model 2 by taking one year lag of all independent variables. After controlling for possible endogeneity the impact of technological investment on outward FDI was persistent along with some other characteristics. The third model was considered the best approach in this paper, as it controlled for possible unobserved heterogeneity. Time averages of all the independent variables were taken as control to account for unobserved heterogeneity that is correlated with the independent variables. This approach works as fixed effect in the model. However, there could be other unobserved heterogeneity which are not correlated with the independent variables, in order to control for that, this model also considers random effect along with fixed effect approach. This model is predicted to be the most robust one among the other models. The results show that, technological investment has a statistical and positive impact on outward FDI. Along with that, investment in knowledge has a statistically significant positive impact on outward FDI. Unlike them, age, size and profit have negative impact on outward FDI. To have more robust results, this paper expands the model using tobit-double hurdle estimation.
\end{abstract}

\section{Keywords:}

Firm level, Microeconometric Analysis, Outward FDI

JEL Classification: C34, D22, C33 